\title{
Click monitoring revisited: An on-line study of sentence comprehension
}

\author{
LAURENT COHEN \\ Service de Neurologie, Hôpital de la Salpêtrière \\ and Laboratoire de Sciences Cognitives et Psycholinguistique, EHESS and CNRS \\ Paris, France \\ and \\ JACQUES MEHLER \\ Laboratoire de Sciences Cognitives et Psycholinguistique, EHESS and CNRS \\ Paris, France
}

\begin{abstract}
Spoken sentence comprehension is based upon rapid and complex psychological processes, yielding a constantly fluctuating cognitive load. The aim of this study was to evaluate on-line click monitoring, a classical but poorly exploited experimental method, which should allow for an easy measurement of processing load at any chosen point of experimental sentences. In Experiments 1 and 2, we obtained longer latencies to clicks located at the boundary of reversible object relative clauses than to clicks identically located in subject relatives and to clicks located earlier within object relatives. Experiment 3 further revealed that this effect of syntactic type was specific to transposed object relatives and did not occur with normal object relatives. In Experiment 4, we observed longer latencies with semantically reversible than with irreversible sentences, but no difference between actives and passives. These results were obtained under strict control of potential lexical and phonological biases, and suggest that on-line click monitoring may be one useful tool in the study of sentence comprehension.
\end{abstract}

In this article we revisit one of the classical methods used to study sentence processing, namely, click monitoring. The basic feature of this method is that subjects have to listen to auditorily presented sentences, with the occurrence of a superimposed short click at some point in the sentence. In most studies using this procedure, subjects have had to report the location of the click as precisely as possible, following each trial. Although this method was first proposed by Ladefoged and Broadbent (1960) with the aim of studying the perception of temporal sequences, it was accorded most attention in the domain of speech perception in the late '60s. In a series of studies, Fodor, Bever, and Garrett (Fodor \& Bever, 1965; Garrett, Bever, \& Fodor, 1966) showed that clicks were subjectively attracted toward clause boundaries, and that their locus was reported more accurately when clicks coincided with major syntactic breaks. These authors suggested that during sentence perception, clauses actually functioned as perceptual units resistant to click intrusion (Fodor, Bever, \& Garrett, 1974). In the late '70s, however, psycholinguists became interested in on-line procedures that could help uncover ongoing sentence comprehension processes. The click-monitoring method was then severely criticized and eventually abandoned. An important objection was that

Correspondence should be addressed to L. Cohen, Service de Neurologie 1, Clinique Paul Castaigne, Hôpital de la Salpêtrière, 47 Bd de l'Hôpital, 75651 Paris Cedex 13, France (e-mail: cohen@lscp.msh-paris.fr). subjects answered long after having heard the sentences, and that their responses might not be a faithful reflection of perceptual processing. In an experiment in which subjects were encouraged to respond even when no click was actually present, Reber (1973) showed that subjects tended to localize nonexistent clicks at syntactic boundaries.

Some authors have proposed an on-line version of the click-monitoring task that requires subjects to press a key as fast as possible as soon as they hear a click, in the hope of obtaining longer latencies when sentence processing becomes more difficult. This expectation is based on the view that syntactic and semantic processes and the click-detection task share limited resources. ${ }^{1}$ Five major studies have relied on the click-monitoring procedure (Abrams \& Bever, 1969; Bond, 1972; Flores d'Arcais, 1978; Green, 1977; Holmes \& Forster, 1970). By and large, these studies suggest that reaction times are shorter in the first than in the second part of sentences, and that reaction is faster to clicks located at major syntactic boundaries than it is to clicks located at minor breaks or within constituents (for a discussion of this, see Cutler \& Norris, 1979).

Recently, two important studies have exported click monitoring to the domain of music perception. Both studies showed that click detection is sensitive to subtle and transient variations in the processing difficulty of musical strings (Berent \& Perfetti, 1993; Stoffer, 1985). However, it is not possible to infer from these results how clicks would behave when superimposed on sentences. Spoken language is spontaneously acquired at an early age, regardless of explicit instruction, and its structure has been 
described by linguists as obeying universal principles. In contrast, music seems to be closer to written language. Widely differing musical systems have been described across cultures, and the amount of overt instruction determines the proficiency of the user, suggesting a more important strategic component than for spoken language (Bever \& Chiarello, 1974). It is therefore conceivable that click detection may share fewer resources with language processing than with music perception.

In the following experiments, we tried to evaluate whether click-monitoring latencies reflect the moment-to-moment difficulty encountered during sentence processing. These experiments were conducted in French, a language in which subject (Example 1) and transposed object relatives (Example 2) differ by only one phoneme in their phonological realization ("qui" vs. "que"), while their syntactic structures are deeply dissimilar:

\section{Le garçon [qui vit la fille]}

The boy [who saw the girl]

\section{Le garçon [que vit la fille]}

*The boy [whom saw the girl]

Thus, object and subject relatives allow for perfect control of all lower level phonological, lexical, and prosodic variables, and seem particularly appropriate for the evaluation of click monitoring. ${ }^{2}$

Off-line methods have shown that object relatives are globally more difficult to understand than subject relatives (e.g., Baird \& Koslick, 1974; Fodor et al., 1974; Holmes, 1979). This was confirmed in on-line studies with visually presented sentences (Ford, 1983; Holmes \& O'Regan, 1981; Wanner \& Maratsos, 1978). Frauenfelder, Segui, and Mehler (1980), working with French speech stimuli and an on-line phoneme-monitoring method, reported a difference between reversible subject (Example 4) and transposed object relatives (Example 5).

4. Le savant [qui connait le docteur] travaille dans une université moderne

The scientist [who knows the doctor] works in a modern university

5. Le savant [que connait le docteur] travaille dans une université moderne

*The scientist [whom knows the doctor] works in a modern university

When the target phoneme was located just after the end of the relative clause (/t/ in "travaille"), latencies were longer for object than for subject relatives. However, no difference was found for a target located before the end of the relative clause (/d/ in "docteur").

The latter results were obtained using semantically reversible sentences. For instance, in Examples 4 and 5, it is equally likely that the scientist knows the doctor and that the doctor knows the scientist. However, no such latency difference was observed between subject and object relatives when using semantically irreversible sentences. Reversibility is not a notion with a syntactic counterpart, but rather reflects the subject's general knowledge of the world. However, the principles along which the syntactic and the semantic components of comprehension processes interact in normal subjects are still a much debated issue (see Garfield, 1987). The supporters of the so-called autonomy of syntax thesis (e.g., Forster, 1979; Frazier, 1987) have proposed that syntax and semantics operate in a strictly sequential fashion, with only the outcome of syntactic processing being submitted to semantic evaluation. It is possible that click detection does not show the same sensitivity to late semantic processes that phoneme monitoring does. As a matter of fact, phoneme monitoring characteristically yields latencies of about $450 \mathrm{msec}$ (Frauenfelder et al., 1980), whereas click detection seems to be nearly twice as fast (Abrams \& Bever, 1969; Holmes \& Forster, 1970). By using the click-detection task, could we tap an earlier processing stage still unaffected by semantic variables?

In the first set of experiments, we tried to replicate Frauenfelder et al.'s (1980) results, using click detection rather than phoneme monitoring. Moreover, we also used a larger set of relative structures: subject, normal object, and transposed object relatives. In the last experiment, the influence of reversibility on click latencies was evaluated with active and passive sentences.

\section{EXPERIMENT 1}

The aim of this experiment was to assess whether click monitoring would yield latencies that were greater at the end of object relatives than at the end of subject relatives, as reported by Frauenfelder et al. (1980) with phoneme monitoring.

Given that we had to present simultaneously two types of auditory stimuli, we had to choose whether to channel clicks and sentences to both ears or to channel clicks to one ear and sentences to the other. In some previous online studies, clicks and sentences were channeled to both ears (Bond, 1972; Flores d'Arcais, 1978; Green, 1977). In another study, sentences were presented to the left ear and clicks to the right ear (Abrams \& Bever, 1969). Only Holmes and Forster (1970) systematically varied the ear of presentation. Half of the subjects received sentences in the right ear and half received them in the left ear, with clicks on the opposite side. Unfortunately, the authors report their data without distinguishing these two conditions. We have thus no direct evidence in favor of one display mode over another. We therefore decided to present clicks and sentences in opposite ears, counterbalancing presentation side within subjects. This procedure provides an opportunity to uncover asymmetries, such as those reported with the off-line click-localization technique (Bertelson \& Tisseyre, 1972; Bever, Lackner, \& Kirk, 1969; Bever, Lackner, \& Stolz, 1969; Fodor \& Bever, 1965). By making clicks more easily perceivable, a dichotic mode of presentation could also induce faster latencies, possibly tapping earlier comprehension processes, with a concomitant risk of reducing all psycholinguistic influences. 


\section{Method}

Materials. Sixteen pairs of semantically reversible sentences containing a relative clause were constructed. Each pair comprised a subject-relative sentence and the corresponding transposed object sentence. The two sentences were identical except for the relative pronouns, which themselves differed by only one phoneme ("qui" vs. "que"). To facilitate click positioning, the word immediately following the relative clause ("travaille" in Examples 4 and 5) always had a stop consonant in initial position.

The experimental sentences were combined with 64 fillers, including 16 relative-clause sentences. To make sure that subjects would not ignore sentences when responding to clicks, the material was interspersed with 14 questions. These were simple questions concerning the preceding sentence and requiring one- or two-word answers.

Two experimental lists were prepared. Each list contained eight subject- and eight object-relative sentences, the two sentences from a given pair being attributed to different lists. The first eight as well as the last eight experimental sentences in each list comprised four object- and four subject-relative sentences. The order of fillers and experimental sentences was identical across the two lists.

The lists were recorded on one track of a magnetic tape. Sentences were separated by a 4-sec interval, and each question was followed by $30 \mathrm{sec}$ of silence. ${ }^{3}$

Clicks that subjects were to detect were positioned on the other track of the stereo tape. They consisted of $12-\mathrm{msec}$ segments of a $1000-\mathrm{Hz}$ sine wave. In the experimental sentences, click onset was synchronized with the burst of the initial phoneme of the word following the end of the relative clause "travaille" in Examples 4 and 5). All but 10 filler sentences carried a click superimposed at a location chosen so as to make the occurrence of clicks unpredictable In fillers with a relative clause, the clicks were never located at the same places as in the experimental sentences.

Procedure. The experimental material was presented dichotically over headphones. Subjects were instructed to react to the clicks as rapidly as possible by pressing a response key. At the same time, in order to write down the correct answers to the questions, they had to pay close attention to the sentences. The timer of a computer was triggered by the click and interrupted by the subject's keypress response.

Subjects. Twenty right-handed Parisian students whose native language was French participated in this experiment. Ten subjects received the first list, and the remaining 10 received the second list Within each list, 5 subjects received the first half of the material with sentences on the left and clicks on the right and the second half with sentences on the right and clicks on the left. The other 5 subjects received the opposite combination.

\section{Results}

Missed targets and latencies longer than $1,000 \mathrm{msec}$ or shorter than $100 \mathrm{msec}$ were excluded from the analyses. Fewer than $1 \%$ of the responses fell into one of these categories. Table 1 displays mean latencies to clicks located on subject and object relatives presented to either the right or the left ear.

Object relatives were responded to $16 \mathrm{msec}$ more slowly than subject relatives $\left[F_{1}(1,18)=7.79, p<.025 ; F_{2}(1,15)=\right.$ $2.47, p<.15] . F_{1}$ and $F_{2}$ refer to analyses of variance with

Table 1

Mean Reaction Time (in Milliseconds) for Experiment 1

\begin{tabular}{|c|c|c|c|}
\hline & \multicolumn{2}{|c|}{ Presentation of Sentences } & \multirow[b]{2}{*}{ Mean } \\
\hline & Right & Left & \\
\hline Subject relative & 220 & 216 & 218 \\
\hline Object relative & 242 & 225 & 234 \\
\hline Difference & 22 & 9 & 16 \\
\hline
\end{tabular}

subjects and items as a random factor, respectively. The interaction between side and syntactic type was not significant $\left[F_{1}(1,18)=1.79 ; F_{2}(1,15)<1\right]$. However, separate analyses showed that when sentences were presented on the right, the 22-msec difference between syntactic types was significant $\left[F_{1}(1,18)=8.55, p<.01 ; F_{2}(1,15)=3.40, p<\right.$ $.1]$, which was not the case for the 9-msec difference observed when sentences were presented on the left $\left[F_{1}(1,18)\right.$ $\left.=1.45 ; F_{2}(1,15)<1\right]$. The overall 10 -msec difference between right and left presentations was not significant.

\section{Discussion}

The overall mean latency reported in the previous section $(226 \mathrm{msec})$ is comparable to those observed in earlier studies by both Abrams and Bever (1969) and Holmes and Forster (1970). Thus, click latencies are much faster than latencies observed in phoneme monitoring studies (Frauenfelder et al., 1980). They appear actually to be closer to simple reaction times to elementary auditory stimuli (Keele, 1986). It was therefore far from certain that click detection would reflect the rather subtle syntactic contrasts in the carrier sentences. However, click detection proved sensitive to the difference between subject and transposed object relatives, nicely replicating Frauenfelder et al.'s (1980) results, even though click-monitoring latencies remain much faster than phoneme-monitoring latencies.

Our results hold when clicks are located at a very particular position in sentences, namely just after the boundary of relative clauses. In Experiment 2, we attempted to replicate the findings of Experiment 1. Additionally, in order to establish whether the contrast between object and subject relatives was restricted to very selective positions or generalized to any position, we tried to compare the two types of structure with clicks located at another position of interest.

\section{EXPERIMENT 2}

Frauenfelder et al. (1980) found a latency difference between subject and object relatives when the target phoneme was located after (extraclause position) but not before (intraclause position) the clause boundary. If click detection was sensitive to the same influences as phoneme monitoring, the advantage of subject over object relatives reported in Experiment 1 should disappear if the click was located before the clause boundary. However, since global reaction times differ notably between these two methods, click detection might reveal differences inaccessible to phoneme monitoring.

The aim of the second experiment was thus twofold. We attempted, first, to replicate the results of the first experiment, using different subjects and sentences. Moreover, we tested whether the replication would hold if more easily detectable clicks were used. Second, we tried to determine whether the effect of syntactic type would generalize to clicks located within the relative clause.

\section{Method}

Materials. Sixteen pairs of semantically reversible sentences containing a relative clause were constructed, obeying the same con- 
straints as in Experiment 1 . In addition, to facilitate click positioning, the last word within the relative clause always had a stop consonant in initial position ("docteur" in Examples 4 and 5).

Experimental sentences were combined with 80 fillers, including 16 relative-clause sentences, and with 16 questions. Two experimental lists were prepared, following the same principles as in Experiment 1 . Two versions of the material were derived from each list. Each version comprised 8 sentences with a click in the intraclause position and 8 sentences with a click in the extraclause position. The first half as well as the second half of each of the four versions of the material comprised 2 experimental sentences in each of the four combinations of syntactic type and click position.

Clicks consisted of $35-\mathrm{msec}$ segments of a $2000-\mathrm{Hz}$ sine wave. The position of extraclause clicks was similar to that of Experiment 1 . Intraclause clicks were synchronized with the initial phoneme of the last word within the relative clause. All but 8 filler sentences carried a click.

Procedure. The instructions and procedure were the same as those described in Experiment 1.

Subjects. Thirty-two right-handed Parisian students whose native language was French participated in this experiment. Eight subjects received each of the four versions of the material. Four of them received the first and the last 48 sentences in the $\mathrm{AB}$ order; the other 4 received them in the BA order. Two subjects in each of these groups of 4 received the first half of the material with sentences on the left and the second half with sentences on the right; the other 2 subjects received the opposite combination.

\section{Results}

Missed targets and latencies over $1,000 \mathrm{msec}$ or under $100 \mathrm{msec}$, which made up less than $1 \%$ of the data, were excluded from the analyses. The overall mean latency of $255 \mathrm{msec}$ was comparable to that observed in Experiment 1.

To evaluate and compare the influence of the syntactic contrast on the detection of clicks located before and after the clause boundary, we first analyzed each of the two positions separately.

Extraclause position. The extraclause condition was designed as a replication of Experiment 1 . Table 2 displays mean latencies to clicks located on subject and object relatives when presented to either the right or the left ear.

Object relatives were responded to $24 \mathrm{msec}$ more slowly than subject relatives $\left[F_{1}(1,30)=5.62, p<.025 ; F_{2}(1,15)=\right.$ $2.32, p<.15]$. This effect tended to be slightly more important when sentences were presented on the right than when they were presented on the left. However, neither the interaction between side and syntactic type $\left[F_{1}(1,30)<1\right.$, $\left.F_{2}(1,15)<1\right]$ nor separate analyses for the right and left sides reached significance [respectively, $F_{1}(1,30)=2.86$ and $2.22 ; F_{2}(1,15)=2.51$ and $\left.<1\right]$.

Intraclause position. Mean reaction times for the two syntactic types and the two sides of presentation are shown in Table 3.

Table 2

Mean Reaction Time (in Milliseconds) for Experiment 2 (Extraclause Position)

\begin{tabular}{lccc} 
& (Extraclause Position) & \\
& \multicolumn{2}{c}{ Presentation of Sentences } \\
\cline { 2 - 4 } & Right & Left & Mean \\
\hline Subject relative & 245 & 250 & 248 \\
Object relative & 274 & 270 & 272 \\
Difference & 29 & 20 & 24 \\
\hline
\end{tabular}

Table 3

\begin{tabular}{|c|c|c|c|}
\hline & \multicolumn{2}{|c|}{ Presentation of Sentences } & \multirow[b]{2}{*}{ Mean } \\
\hline & Right & Left & \\
\hline Subject relative & 242 & 256 & 249 \\
\hline Object relative & 241 & 259 & 250 \\
\hline Difference & -1 & 3 & 1 \\
\hline
\end{tabular}

Inspection of the data clearly shows that there was no latency difference between syntactic types, either globally or separately on either side [all $F_{1}(1,30)<1$; all $F_{2}(1,15)<$ 1]. The 16-msec difference between left and right presentation did not reach significance $\left[F_{1}(1,30)=2.22, p<.15\right.$; $\left.F_{2}(1,15)=2.49, p<.15\right]$, and there was no interaction between side and syntactic type $\left[F_{1}(1,30)<1 ; F_{2}(1,15)<1\right]$.

Effect of click position. So far we have conducted separate analyses aimed at comparing monitoring latencies between similar locations in different sentences. However, click detection is also expected to disclose fluctuations of processing difficulty within a given sentence. Does the latency difference between subject and object relatives reflect a local increase in processing load for object relatives or a local decrease for subject relatives? To address this question, we now consider both the intra- and extrarelative positions within a single analysis.

As shown in Table 4, all mean latencies were about $250 \mathrm{msec}$ except when the click was in extraclause position for object relatives, yielding a $272-$ msec mean latency. Reaction times to object relatives were $22 \mathrm{msec}$ slower in the extraclause position than in the intraclause position, a difference that was marginally significant $\left[F_{1}(1,30)=3.81, p<.07 ; F_{2}(1,15)=4.22, p<.06\right]$. There was obviously no position effect for subject relatives. However, the interaction between syntactic type and position was only marginally significant by subjects $\left[F_{1}(1,30)=\right.$ $3.40, p<.08 ; F_{2}(1,15)=1.39$ ].

\section{Discussion}

The difference between object and subject relatives already observed in Experiment 1 was replicated in Experiment 2 using different sentences and subjects, thus confirming the potential usefulness of on-line click detection in the study of sentence processing. For clicks in extrarelative position, the mean detection latency was $24 \mathrm{msec}$ longer for object than for subject sentences, a difference similar to the $16 \mathrm{msec}$ observed in Experiment 1, where reaction times were on the whole somewhat shorter.

Analysis of variance with items as a random factor uncovered only a marginally significant effect of syntactic type in both Experiment 1 and Experiment 2. This outcome is not too surprising given the somewhat limited number of data points in each condition. However, if Experiments 1 and 2 are pooled, with experiment being treated as a between-items factor, the difference between object and subject relatives with clicks in the extraclause position proves statistically reliable by items $\left[F_{2}(1,30)=4.45, p<.05\right]$. A significant effect of syntactic type appears in a similar 
Table 4

Mean Reaction Time (in Milliseconds) for Experiment 2

\begin{tabular}{|c|c|c|c|}
\hline & \multicolumn{2}{|c|}{ Syntactic Type } & \multirow[b]{2}{*}{ Mean } \\
\hline & Subject & Object & \\
\hline Intraclause & 249 & 250 & 250 \\
\hline Extraclause & 248 & 272 & 260 \\
\hline Difference & -1 & 22 & 10 \\
\hline
\end{tabular}

analysis restricted to sentences presented on the right $\left[F_{2}(1,30)=5.34, p<.03\right]$ but not to sentences presented on the left $\left[F_{2}(1,30)<1\right]$. Considering the fact that the same pattern of results was observed in both experiments, using different sets of sentences, it seems unlikely that the syntactic effect should result from some uncontrolled property of only a small subset of object relatives.

Furthermore, there was no trace of a syntactic effect when clicks were located before the relative clause boundary. In all experimental conditions, mean reaction times were about $250 \mathrm{msec}$, except for object relatives with the click in late position, where the mean latency was $272 \mathrm{msec}$. This result is similar to Frauenfelder et al.'s (1980) finding with phoneme monitoring, suggesting that despite a global speed difference these two methods may prove to be sensitive to the same phenomena.

These results are consonant with all previous studies showing that object relatives are more difficult to process than subject relatives. However, we used only transposed object relatives, while most existing studies are limited to the English language in which such structures do not exist. Therefore, it is not clear whether the local increase of processing load that we have observed in object relatives is specific to the transposed variant, as opposed to the normal variant, which is both structurally simpler and easier to understand (Holmes \& O'Regan, 1981). This issue was addressed in the next experiment.

\section{EXPERIMENT 3}

In the preceding experiments, a latency difference between subject and transposed object relatives was observed in the extraclause position. The aim of the third experiment was to see whether the same difference would arise with the normal stylistic variant of object relatives.

\footnotetext{
Method

Materials. Sixteen pairs of semantically reversible sentences containing a relative clause were constructed, obeying the same constraints as in Experiment 1. The click was preceded by a noun in subject relatives ("docteur" in Example 4) and by a verb in object relatives ("connait" in Example 6). Since the syllabic length of the preceding word has been shown to influence detection of the initial phoneme of words (Mehler, Segui, \& Carey, 1978), these two words comprised the same number of syllables within each pair of sentences.

6. Le savant [que le docteur connait] travaille dans une université moderne

The scientist [whom the doctor knows] works in a modern university
}

Experimental sentences were combined with 89 fillers, including 10 relative-clause sentences, and with 10 questions. Two experimental lists were prepared, following the same principles as in Experiment 1.

In the experimental sentences, clicks were synchronized with the burst of the initial phoneme of the word following the end of the relative clause. All filler sentences carried a click located at randomly diversified positions.

Procedure. The instructions and procedure were the same as those in Experiments 1 and 2.

Subjects. The subjects were 32 right-handed Parisian students whose native language was French. Sixteen subjects received the first list, and the remaining 16 received the second list. Within each list, 8 subjects received the first half of the material with sentences on the left and clicks on the right and the second half with sentences on the right and clicks on the left. The other 8 subjects received the opposite combination.

\section{Results}

Missed targets, response times longer than $1,000 \mathrm{msec}$ or shorter than $100 \mathrm{msec}$, which made up $1 \%$ of the data, were excluded from the analyses.

As indicated in Table 5, there was no latency difference between clicks located after the clause boundary in subject relatives or in normal object relatives. There was no significant effect of presentation side and no interaction of these factors [all $F_{1}(1,30)<1$; all $F_{2}(1,15)<1$ ].

\section{Discussion}

The absence of an increase in processing load after normal object relatives suggests that the results of Experiments 1 and 2 were specific to the transposed variant. One major advantage of the experiments reported so far is that they made use of very different underlying syntactic structures that were nevertheless very similar in their superficial realization. However, the results of Experiment 3 suggest that this advantage may have some drawbacks as well. Thus, the very similarity of subject and transposed object relatives may be confusing to the listeners. Transposed object relatives are rarely used in conversational speech (Noizet, Deyts, \& Deyts, 1972) and may occasionally be misinterpreted as subject relatives, whose structure is more familiar (Holmes \& O'Regan, 1981).

Given this situation, the best way to extend the scope of our investigations was to move to other kinds of structures that share important syntactic features with relatives while escaping the difficulties that might result from the superficial resemblance of the sentences to be compared. Moreover, it should be remembered that the latency difference between object and subject relatives observed by Frauenfelder et al. (1980) disappeared when semantically irreversible sentences were used. To elucidate the influence of

Table 5

Mean Reaction Time (in Milliseconds) for Experiment 3

\begin{tabular}{|c|c|c|c|}
\hline & \multicolumn{3}{|c|}{ Presentation of Sentences } \\
\hline & Right & Left & Mean \\
\hline Subject relative & 265 & 259 & 262 \\
\hline Object relative & 269 & 259 & 264 \\
\hline Difference & 4 & 0 & 2 \\
\hline
\end{tabular}


reversibility on click monitoring, structures that could incorporate reversibility constraints seemed also desirable.

In the next experiment, we pursued these issues in two ways. First, in an attempt to extend our initial findings to different, albeit similar, structures, we explored the perception of active versus passive sentences. Second, to explore the influence of the semantic content of sentences on click monitoring, we independently manipulated semantic reversibility.

\section{EXPERIMENT 4}

The relationship between active and passive sentences is in several respects similar to the relationship between subject and transposed object relatives. Reciprocal conversion from one syntactic form to the other is realized mainly through an inversion of the linear order of the arguments. In simple active sentences and in subject relatives, the agent comes first, followed by the verb and the logical object (Example 7), whereas in passive sentences, just as in transposed object relatives, the logical object comes first followed by the verb and the agent (Example 8).

7. The boy has eaten the apple

The boy who has eaten the apple

8 . The apple was eaten by the boy The apple that was eaten by the boy

Additionally, the two forms are distinguished by specific grammatical markers. In optimal cases, the only visible difference is the adjunction, in the passive form, of the auxiliary verb "été" (been) and of the preposition "par" (by) preceding the agent (Examples 9 and 10). Synonymous and superficially similar, but nonetheless structurally quite different, sets of sentences can thus be conveniently constructed and studied.

Resorting to memory tasks (Mehler, 1963; Savin \& Perchonock, 1965) or to sentence picture verification tasks (Gough, 1965, 1966; Slobin, 1966), early off-line studies have shown that passive sentences are globally more difficult to process than the corresponding active sentences. There were additional indications that the increased difficulty of passives was restricted to semantically reversible sentences and spared irreversible sentences containing strong semantic clues to the correct analysis (Herriot, 1969; Slobin, 1966). However, this interaction could not be replicated using different experimental methods (Forster \& Olbrei, 1973), suggesting that these results did not reflect on-line sentence processing. These issues remain largely unsettled, especially due to the dearth of on-line studies of passive versus active sentence comprehension.

In this experiment, syntactic type (active vs. passive) and semantic reversibility were controlled independently in order to assess their respective influence on click-detection latencies.

\section{Method}

Materials. Sixteen sentences were constructed, each existing in four different versions: reversible active, reversible passive, irreversible active, and irreversible passive. As mentioned before, reversible ac- tive and reversible passive sentences differed only by the two words "été" and "par" (Examples 9 and 10).

9. Le sénateur a décoré le député dimanche dernier The senator has decorated the deputy last Sunday

10. Le sénateur a été décoré par le député dimanche dernier The senator was decorated by the deputy last Sunday

There were necessarily some additional lexical differences between the two irreversible forms, generally affecting the subject and the verb (Examples 11 and 12).

11. La bombe a blessé le député dimanche dernier The bomb has injured the deputy last Sunday

12. Le banquet a été présidé par le député dimanche dernier The banquet was presided by the deputy last Sunday

More importantly, the second noun as well as the two following words were identical in the four versions of all 16 sentences ("le député dimanche dernier"). To facilitate click positioning, the word immediately following the second noun ("dimanche") always had a stop consonant in initial position.

The experimental sentences were combined with 51 fillers and 18 questions. Four experimental lists were prepared following the same principles as in previous experiments. Each list contained four sentences in each of the four combinations of reversibility (reversible vs. irreversible) by syntactic type (active vs. passive), equally distributed between the first and second halves.

In experimental sentences, clicks were synchronized with the burst of the initial phoneme of the word following the second noun (/d/ in "dimanche" in Examples 9 to 12). All filler sentences carried a click located at randomly diversified positions.

Procedure. The instructions and procedure were the same as those in Experiments 1 to 3.

Subjects. The subjects were 40 right-handed Parisian students whose native language was French. Ten subjects received each of the four experimental lists. Within each list, 5 subjects received the first half of the material with sentences on the left and clicks on the right and the second half with sentences on the right and clicks on the left. The other 5 subjects received the opposite combination.

\section{Results}

Missed targets, response times longer than $1,000 \mathrm{msec}$ or shorter than $100 \mathrm{msec}$, which made up $1 \%$ of the data, were excluded from the analyses. Mean reaction times for each condition of semantic reversibility and syntactic type are displayed in Table 6.

Clicks were detected $17 \mathrm{msec}$ more slowly in reversible sentences than in irreversible sentences $\left[F_{1}(1,36)=8.79\right.$, $\left.p<.006 ; F_{2}(1,15)=2.51, p<.15\right]$. Both active and passive sentences were affected to the same degree by the semantic effect (18 and $15 \mathrm{msec}$, respectively). Accordingly, there was no significant interaction between reversibility and syntactic type $\left[F_{1}(1,36)<1 ; F_{2}(1,15)<1\right]$. There was no significant effect of syntactic type, of presentation side, and no interaction of these factors (all $F_{1}(1,36)<1$; all $\left.F_{2}(1,15)<1\right]$.

Table 6

Mean Reaction Time (in Milliseconds) for Experiment 4

\begin{tabular}{lccc}
\multicolumn{4}{c}{ Mean Reaction Time (in Milliseconds) for Experiment 4 } \\
\cline { 2 - 3 } & \multicolumn{2}{c}{ Syntactic Type } & \\
\cline { 2 - 4 } & Active & Passive & Mean \\
\hline Reversible & 296 & 294 & 295 \\
Irreversible & 278 & 279 & 278 \\
Difference & 18 & 15 & 17 \\
\hline
\end{tabular}


It is worth mentioning that, as indicated in Table 7, the effect of reversibility tended to be larger when sentences were presented on the right $\left[25 \mathrm{msec}: F_{1}(1,36)=9.38\right.$, $\left.p<.005 ; F_{2}(1,15)=2.65, p<.13\right]$ than when they were presented on the left $\left[8 \mathrm{msec}: F_{1}(1,36)=1.01 ; F_{2}(1,15)<\right.$ 1]. However, the interaction between reversibility and side was not significant $\left[F_{1}(1,36)<1 ; F_{2}(1,15)<1\right]$.

\section{Discussion}

The main goal of this experiment was to compare active and passive sentences while controlling reversibility as a way to extrapolate the validity of on-line click detection beyond the limited case of relatives. At first glance, the outcome of this experiment was somewhat unexpected. We had stressed the similarity between active versus passive sentences and subject versus transposed object relatives, expecting that a latency difference between actives and passives would emerge; this was not the case. The precise meaning of these results, as well as those of the experiments on relative clauses, will be discussed in the following section.

However, we did observe a reliable latency difference between reversible and irreversible sentences, affecting active as well as passive structures. This effect is in several respects similar to that of relative type reported in Experiments 1 to 3 . Both effects have the same order of magnitude and tend to be larger when sentences are presented on the right. We will take these observations as useful hints when discussing the bases of the click method.

\section{GENERAL DISCUSSION}

In the present series of experiments, several results have emerged with some clarity. Experiments 1 and 2 show latencies that are longer to clicks located at the boundary of reversible object relatives than to clicks identically located in subject relatives and to clicks located one word earlier within object relatives. Experiment 3 reveals that this effect is specific to transposed object relatives and does not occur with normal object relatives. Experiment 4 shows that despite their resemblance to subject and transposed object relatives, respectively, active and passive sentences do not yield significantly different mean latencies. Finally, reaction times are significantly longer to reversible sentences than to irreversible sentences, irrespective of their active or passive type.

When perceiving speech, listeners try to attribute to each argument a role relative to the verbs in the sentence ("who did what to whom"). To this end, two main sources of information come into play, in addition to the meaning

Table 7

Mean Reaction Time (in Milliseconds) for Experiment 4

Presentation of Sentences

\begin{tabular}{ccc}
\hline Right & Left & Mean \\
\hline 298 & 292 & 295 \\
273 & 284 & 278 \\
25 & 8 & 17 \\
\hline
\end{tabular}

of each individual word. First, purely structural clues, such as word order and grammatical morphemes, are analyzed by a syntactic parser which, according to some researchers, is largely blind to the meaning of open-class words (e.g., Ferreira \& Clifton, 1986; Frazier, 1987). Second, the meaning of open-class morphemes may also indicate how to combine words in a semantically most plausible way, irrespective of their actual position in the sentence. This semantic information receives its value from the listener's knowledge of the real world, and may be the only clue to sentence comprehension in brain-lesioned patients with impaired syntactic processing (Caramazza \& Zurif, 1976).

In Experiments 1 to 3, we used only reversible sentences, thus minimizing the effect that the subjects' knowledge of the world might have on the ongoing comprehension processes. It would therefore seem natural that the latency difference between subject and transposed object relatives should directly reflect the difficulty of the syntactic analysis. As indicated before, transposed object relatives are perceptually difficult to distinguish from the much more frequent subject relatives, from which they differ by only one phoneme (Noizet et al., 1972). Indeed, transposed object relatives are known to be frequently misunderstood, that is, probably interpreted as subject relatives (Holmes \& O'Regan, 1981). Listeners are confronted, on the one hand, with a word order statistically most suggestive of a subject relative and, on the other, with the perceptually doubtful grammatical word "que," indicative of an object relative. It is therefore plausible that at this point subjects engage in a verification process, taking resources away from click monitoring. This hypothesis accounts naturally for the absence of an increase of click latency with normal object relatives as compared with subject relatives, but also with passive as compared with active sentences. There is, indeed, no structural uncertainty with normal object relatives. In agreement with the pronoun "que," the word order is a salient and unambiguous indication that the listener is dealing with an object relative. Similarly, passive sentences contain at least two additional grammatical words as opposed to actives (the auxiliary verb and the preposition "par" preceding the agent). In short, listeners do not encounter any structural ambiguity when dealing with subject relatives and passive sentences, and costly verification procedures are not called for.

Could a similar phenomenon account also for the longer mean latency obtained with reversible than with irreversible sentences? Irreversible sentences have only one plausible interpretation, whereas in reversible sentences, the two interpretations that are compatible with the meaning of individual words appear to be semantically equally good. In the latter case, this indetermination may trigger verification procedures responsible for a slowing of click detection.

We may thus submit a tentative characterization of all click-monitoring effects observed at the sentence level. As soon as the listener has heard a verb and its attached arguments, a final interpretation must be reached on the joint basis of syntactic clues and semantic plausibility. If each of these sources of information provides a clear-cut 
analysis (and presumably if these two analyses are congruent), a decision can be reached with minimal effort and response to clicks is fast. On the other hand, constructions that are either syntactically unfamiliar and confusable (such as transposed object relatives) or semantically ambiguous (such as reversible sentences) may trigger reanalysis or at least a verification check. In such cases, fewer resources are available for click monitoring and latencies are therefore longer.

Although the interaction with side of presentation never reached significance, all observed effects tended to be larger when sentences were presented on the right and clicks on the left. The consistency of this trend over experiments deserves a short commentary. It may be related to the right-ear advantage for language evidenced in a wide variety of tasks where a linguistic stimulus is presented in one ear often simultaneously with another linguistic or nonlinguistic stimulus in the opposite ear (for reviews, see Bradshaw \& Nettleton, 1988, and Bryden, 1988). This advantage is considered to result more or less directly from the left-hemispheric specialization for language, associated with predominant associations of each ear with the contralateral hemisphere (for contrasting views, see, e.g., Kimura, 1967, and Kinsbourne, 1970). Although no definitive conclusion is now possible concerning click monitoring, two hypotheses may be considered. It is possible that sentences receive less attention when they appear on the left side and are therefore processed more superficially. Accordingly, previous studies have shown that sentences are memorized less effectively when they are presented on the left than when they are presented on the right (e.g., Jarvella \& Herman, 1973). Alternatively, it may be that sentences are processed essentially in the same way in the two conditions, but that sentence comprehension and click monitoring do not interact identically depending on the side of presentation. Let us assume that linguistic stimuli presented on the right benefit from a temporal priority of access to attentional resources. With the encounter of an instantaneous processing difficulty (for instance at the end of transposed object relatives), response to the click would be postponed until the difficulty was solved. Conversely, language would have no such priority when presented on the left and comprehension processes would be interrupted by the click whose detection would not be delayed.

At any rate, these observations suggest that it may be possible to increase the sensitivity of click monitoring by systematically avoiding the presentation of linguistic stimuli in the left ear and by biasing the subjects' strategy toward a deeper processing of sentences. This could be achieved simply by increasing the number or the difficulty of the questions or by providing subjects with feedback on the quality of their answers.

In conclusion, click monitoring seems to be a suitable method for uncovering strategic processes in which subjects engage in the late attentive stages of speech perception. In contrast, click monitoring latencies appear to be immune to the influence of the obligatory processes that intervene during the early stages of sentence processing. Further studies are needed in order to confirm and exploit the sensitivity of clicks to sentence-level processes, as well as to explore their potential usefulness in the study of lower levels of processing, such as phonology or the lexicon.

\section{REFERENCES}

Abrams, K., \& Bever, T. G. (1969). Syntactic structure modifies attention during speech perception and recognition. Quarterly Journal of Experimental Psychology, 21, 280-290.

BAIRD, R., \& Koslick, J. D. (1974). Recall of grammatical relations within clause-containing sentences. Journal of Psycholinguistic Research, 3, 165-171.

Berent, I., \& Perfetti, C. A. (1993). An on-line method in studying music parsing. Cognition, 46, 203-222.

Bertelson, P., \& Tisseyre, F. (1972). Lateral asymmetry in the perceived sequence of speech and nonspeech stimuli. Perception \& Psychophysics, 11, 356-362.

Bever, T. G., \& Chiarello, R. J. (1974, August 9). Cerebral dominance in musicians and nonmusicians. Science, 185, 537-539.

Bever, T. G., LACKNER, J. R., \& KIRK, R. (1969). The underlying structures of sentences are the primary units of immediate speech processing. Perception \& Psychophysics, 5, 225-234.

Bever, T. G., Lackner, J. R., \& Stolz, W. (1969). Transitional probability is not a general mechanism for the segmentation of speech. Journal of Experimental Psychology, 79, 387-394.

Bond, Z. S. (1972). Phonological units in sentence perception. Phonetica, 25, 129-139.

Bradshaw, J. L., \& Nettleton, N. C. (1988). Monaural asymmetries. In K. Hugdahl (Ed.), Handbook of dichotic listening: Theory, methods and research (pp. 45-69). New York: Wiley.

BRYDEN, M. P. (1988). An overview of the dichotic listening procedure and its relation to cerebral organization. In K. Hugdahl (Ed.), Handbook of dichotic listening: Theory, methods and research (pp. 1-43). New York: Wiley.

CaramazZA, A., \& Zurif, E. B. (1976). Dissociation of algorithmic and heuristic processes in language comprehension: Evidence from aphasia. Brain \& Language, 5, 572-583.

Cutler, A., \& NorrIS, D. (1979). Monitoring sentence comprehension. In W. E. Cooper \& E. C. T. Walker(Eds.), Sentence processing: Psycholinguistic studies presented to Merrill Garrett (pp. 113-134). Hillsdale, NJ: Erlbaum.

Ferreira, F., \& Clifton, C. (1986). The independence of syntactic processing. Journal of Memory \& Language, 25, 348-368

FloRES D'ARCAIS, G. B. (1978). The perception of complex sentences. In W. J. M. Levelt \& G. B. Flores d'Arcais (Eds.), Studies in the perception of language (pp. 155-185). Chichester, U.K.: Wiley.

Fodor, J. A., \& BEvER, T. G. (1965). The psychological reality of linguistic segments. Journal of Verbal Learning \& Verbal Behavior, 4, 414-420.

Fodor, J. A., Bever, T. G., \& GarretT, M. F. (1974). The psychology of language. New York: McGraw-Hill.

FORD, M. (1983). A method for obtaining measures of local parsing complexity throughout sentences. Journal of Verbal Learning \& Verbal Behavior, 22, 203-218.

FORSTER, K. (1979). Levels of processing and the structure of the language processor. In W. E. Cooper \& E. C. T. Walker (Eds.), Sentence processing: Psycholinguistic studies presented to Merrill Garrett (pp. 27-85). Hillsdale, NJ: Erlbaum.

Forster, K., \& Olbrei, I. (1973). Semantic heuristics and syntactic analysis. Cognition, 23, 319-347.

Frauenfelder, U., Segul, J., \& Mehler, J. (1980). Monitoring around the relative clause. Journal of Verbal Learning \& Verbal Behavior, 19, 328-337.

FraZiER, L. (1987). Theories of sentence processing. In J. L. Garfield (Ed.), Modularity in knowledge representation and natural language understanding (pp. 493-522). Cambridge, MA: MIT Press.

GARFIELD, J. L. (1987). Modularity in knowledge representation and natural language understanding. Cambridge, MA: MIT Press.

Garrett, M. [F.], Bever, T. [G.], \& Fodor, J. [A.] (1966). The active use of grammar in speech perception. Percepition \& Psychophysics, 1 , 30-32. 
GovGH, P. B. (1965). Grammatical transformations and speed of understanding. Journal of Verbal Learning \& Verbal Behavior, 4, 107-111.

GovGH, P. B. (1966). The verification of sentences: The effect of delay of evidence and sentence length. Journal of Verbal Learning \& Verbal Behavior, 5, 492-496.

GrEeN, D. W. (1977). The immediate processing of sentences. Quarterly Journal of Experimental Psychology, 29, 135-146.

HerRIOT, P. (1969). The comprehension of active and passive sentences as a function of pragmatic expectations. Journal of Verbal Learning \& Verbal Behavior, 8, 166-169.

HoLmEs, V. M. (1979). Some hypotheses about syntactic processing in sentence comprehension. In W. E. Cooper \& E. C. T. Walker (Eds.), Sentence processing: Psycholinguistic studies presented to Merrill Garrett (pp. 227-248). Hillsdale, NJ: Erlbaum.

HOLMES, V. M., \& ForSTER, K. I. (1970). Detection of extraneous signals during sentence recognition. Perception \& Psychophysics, 7, 297-301.

Holmes, V. M., \& O'Regan, J. K. (1981). Eye fixation patterns during the reading of relative-clause sentences. Journal of Verbal Learning \& Verbal Behavior, 20, 417-430.

JARVELLA, R. L., \& HERMAN, S. J. (1973). Speed and accuracy of sentence recall: Effects of ear of presentation, semantics, and grammar. Journal of Experimental Psychology, 97, 108-110.

KeELE, S. W. (1986). Motor control. In K. R. Boff, L. Kaufman, \& J. P Thomas (Eds.), Handbook of perception and human performance (Vol. 2, pp. 30-1 to 30-60). New York: Wiley.

KIMURA, D. (1967). Functional asymmetry of the brain in dichotic listening. Cortex, 3, 163-178.

KInSBOURNE, M. (1970). The cerebral basis of lateral asymmetries in attention. Acta Psychologica, 33, 193-201.

Ladefoged, P., \& Broadbent, D. E. (1960). Perception of sequence in auditory events. Quarterly Journal of Experimental Psychology, 13 162-170.

MEHLER, J. (1963). Some effects of grammatical transformations on the recall of English sentences. Journal of Verbal Learning \& Verbal Behavior, 2, 346-351.

MeHLeR, J,, Segui, J., \& CAREY, P. (1978). Tails of words: Monitoring ambiguity. Journal of Verbal Learning \& Verbal Behavior, 17, 29-35.

NoIZet, G., Deyts, F., \& DeYTs, J. P. (1972). Producing complex sentences by applying relative transformations. Linguistics, 89, 49-67.

REBER, A. S. (1973). Locating clicks in sentences: Left, center, and right. Perception \& Psychophysics, 13, 133-138.

SAVIN, H. B., \& PERCHONOCK, E. (1965). Grammatical structure and the immediate recall of English sentences. Journal of Verbal Learning \& Verbal Behavior, 4, 348-353.

SLOBIN, D. (1966). Grammatical transformations and sentence comprehension in childhood and adulthood. Journal of Verbal Learning \& Verbal Behavior, 5, 219-227.
STOFFER, T. H. (1985). Representation of phrase structure in the perception of music. Music Perception, 3, 191-220.

WanNer, E., \& MaraTsos, M. (1978). An ATN approach to comprehension. In M. Halle, J. Bresnan, \& G. A. Miller (Eds.), Linguistic theory and psychological reality (pp. 119-159). Cambridge, MA: MIT Press.

\section{NOTES}

1. From now on, we will use "click monitoring" to refer only to the online version of the task.

2. The function of relative clauses is to modify a noun phrase, called the "head" of the relative clause, which they immediately follow. Relative clauses are structurally akin to simple declarative clauses, except that one noun phrase appears to be missing. In addition to its function in the main clause in which the relative is embedded, the head has an implicit function within the relative clause. This function corresponds to that of the missing within-clause constituent. In subject relatives (Example 1), there is no visible subject in the relative clause, meaning that the head ("the boy") should actually be understood as the subject of "saw." Similarly, in object relatives (Example 3), the within-clause object is missing and the head should be construed as the object of "saw":

3. Le garçon [que la fille vit]

The boy [whom the girl saw]

French object relatives may assume two different but semantically equivalent forms. Normal object relatives are strictly equivalent to the corresponding English structure (Example 3), whereas, in so-called transposed object relatives, the clause internal subject ("the girl") has been moved to the end of the relative clause (Example 2).

3. To make sure that the relative pronoun ("qui" vs. "que") was the only indication of the syntactic type, and in particular that there be no systematic prosodic difference between subject and object relatives, the experimental sentences were low-pass filtered at $275 \mathrm{~Hz}$, so as to erase as much phonemic information as possible while keeping prosody intact. The 32 filtered sentences were presented to 10 subjects in random order. The subjects were asked to decide to which category (subject or object) each sentence belonged, with the suggestion that they use prosodic clues as much as possible. Feedback was provided for the first six trials. The subjects' performance was not better than chance $\left[\chi^{2}(1)=1.38, p=.24\right]$, confirming that prosody was not significantly different in subject and object relatives.

(Manuscript received August 19, 1994; revision accepted for publication February 15, 1995.) 